\title{
HERMENÊUTUCA-FENOMENOLÓGICA COMO METODOLOGIA EM LINGUISTICA APLICADA
}

\section{PHENOMENOLOGICAL HERMENEUTICS AS METHODOLOGY IN APPLIED LINGUISTICS}

\author{
Eduardo Dias da Silva ${ }^{1}$
}

\begin{abstract}
Resumo: neste artigo são apresentadas as características da metapesquisa qualitativa na modalidade de análise documental e, assim, faz-se uso da perspectiva hermenêutica-fenomenológica de Ricoeur (1976; 1978; 1989; 1990) e de Gadamer (1977; 2010), referencial metodológico adotado em nossa dissertação de mestrado, cujo artigo é um recorte. O foco na abordagem da hermenêutica-fenomenológica visou à identificação do texto teatral, do corpo e da voz como contribuintes para o (re)conhecimento da realidade na qual explica os motivos da utilização dos construtos citados como mediadores na apropriação da oralidade no ensino-aprendizagem de Língua Estrangeira (LE). Assim, justifica-se a nossa escolha da perspectiva hermenêutica-fenomenológica em suas conceptualizações e formulações (atemporais) pertencentes a uma época distinta que pelas suas contribuições, mundialmente reconhecidas, tornaram-se fontes de abordagem metodológica, ao longo dos tempos, já difundidas e bem aclamadas nos campos da Educação, dos Estudos Literários, da Psicologia, da Filosofia, dentre outros. Ressalta-se também o ineditismo deste artigo e o nosso latente interesse na aplicação da abordagem metodológica na área de Linguística Aplicada (LA). Discorre-se também sobre o caráter documental, a distinção entre metapesquisa e estudo-da-arte na tentativa de elucidar eventuais ruídos terminológicos e metodológicos nos nossos apontamentos e para melhor formular nossos preceitos de metodologia.
\end{abstract}

Palavras-chave: Hermenêutica-fenomenológica; Linguística Aplicada; Metodologia; Metapesquisa; Ricoeur e Gadamer.

Abstract: On this qualitative, documental and interpretative metasearch article, the phenomenological and hermeneutic perspective of Ricoeur (1976; 1978; 1989; 1990) and Gadamer (1977; 2010) - methodological framework endorsed in our Master's thesis. This article is cut-out from the thesis. The phenomenological hermeneutics focuses on theatrical text, body and voice identification as contributors for there cognition/knowledge of the reality. In this reality, the reasons for using the constructs mentioned as mediators in orality appropriation in the Foreign Language (LE) teachinglearning process are explained. Thus, our choice is justified - our choice for the phenomenological hermeneutics perspective on its (timeless) concepts and formulations which belong to a certain age. Their contributions recognised all over the world became methodological approach sources throughout time, being spread out and hailed in Education, Literary Studies, Psychology and Philosophy areas. The uniqueness of this article and our latent interest on applying the methodological approach in Applied Linguistic (LA) area are here enhanced. Finally, the article is also about documental char-

${ }^{1}$ Licenciado em Letras Francês - língua e literatura - pela Universidade de Brasília (UnB); especialista em Metodologia de Ensino em língua Portuguesa e Estrangeira pela Uninter; e mestre em Linguística Aplicada pela (UnB). Atualmente é professor de Francês Língua Estrangeira (FLE) na SEE/DF - CILSOB. 
acter, the distinction between metasearch and art study when trying to explain possible terminological and methodological noises in our notes and to better formulate our methodological precepts.

Keywords: Phenomenological hermeneutics; Applied Linguistics; Methodology; Metasearch; Ricoeur and Gadamer.

Para as pesquisas documentais qualitativas, a realidade é compreendida como fluente e contraditória, e os processos de investigação são vistos como dependentes das concepções, valores e objetivos do pesquisador, como defende Chizzotti (2006). Seguindo a mesma lógica, Moura Filho (2000) destaca que esse tipo de pesquisa enfatiza a natureza da realidade socialmente construída, a relação entre o pesquisador e o contexto, e as restrições que podem ocorrer.

O valor "documental" não está intimamente ligado somente ao produto escrito, "o termo documental alude a materiais escritos, visuais ou físicos", conforme afirma Merriam (1998, p. 112). Na análise documental há, caso necessário, a opção de analisar as informações contidas nos documentos concomitantemente com outros instrumentos de coletas (entrevistas) e/ou outros instrumentos de registros, que não foram aplicados a esta pesquisa. Em todos os casos, o primordial é que tais documentos sejam relevantes ao estudo em questão. No que tange ainda à definição de análise documental, Santos (2013) concebe que

é um meio de pesquisa e de geração de dados que, em pesquisas de natureza qualitativa, pode tanto servir para complementar as informações já obtidas via outras técnicas quanto evidenciar novos aspectos ligados a uma temática específica (p. 107).

Neste artigo, os documentos foram fontes que forneceram dados referentes ao uso do texto teatral, do corpo e da voz como mediadores na apropriação da oralidade no ensino-aprendizagem de Língua Estrangeira (LE) para serem analisados "sistematicamente". Portanto, os documentos são como "quaisquer materiais escritos que possam ser usados como fonte de informação sobre o comportamento humano", conforme Phillips (1974, p. 187 apud Lüdke; André, 1986, p. 38), tais quais leis, diários, jornais, revistas, discursos, 
livros, arquivos escolares, entre outros de acordo com Lüdke e André (1986) e Flick (2009). Os documentos aos quais se faz referência são dissertações de mestrado, teses de doutorado, livros e artigos de dois professores metapesquisados, a saber: Massaro (2001; 2007; 2008), da USP, e Reis (2008; 2011; 2012), da UnB. Há outra definição bastante relevante para "documentos" que traduz melhor a concepção que se tem em relação a eles, que é a seguinte:

Se tivermos que arcar com a natureza dos documentos, então precisaremos afastar-nos de um conceito que os considere como artefatos estáveis, estáticos e pré-definidos. Em vez disso, devemos considerá-los em termos de campos, de estruturas e de redes de ação. De fato, o status das coisas enquanto "documentos" depende precisamente das formas como esses objetos estão integrados nos campos de ação, e os documentos só podem ser definidos em relação a esses campos (PRIOR, 2003, p. 2 apud FLICK, 2009, pp. 230-231).

É de se vislumbrar, a partir da citação, que "documentos" são despidos de uma concepção estável, ou seja, eles são retirados de uma forma com molde fixo e preestabelecido, passando a significar registros escritos/visuais/auditivos inseridos em um momento sócio-histórico específico. Os significados dos documentos, nesses termos, são construídos a partir da inserção no social, momento em que "documentos" e "meio social" se relacionam dialeticamente. Os documentos enquanto discursos são restringidos pelo social, mas também o constitui. Assim, é nas práticas discursiva (quem produziu, onde, local de circulação, quem consome) e social (relações de poder, ideologia, hegemonia) que os documentos são definidos.

Tal concepção de documento apresentada leva a enxergá-los para além dos textos escritos em seus aspectos linguístico-estruturalistas, ajudando na tarefa de análise à medida que é lembrado de que analisar um documento é, segundo Flick, "mais do que mera análise de textos" (2009, p. 232). Portanto, na análise documental, os documentos são explorados como "dispositivos comunicativos em vez de contêineres de conteúdos” (p. 236).

A análise documental se difere da bibliográfica, pois enquanto esta utiliza fontes secundárias, ou seja, materiais disponibilizados já analisados por outros especialistas, aquela utiliza fontes primárias, cujos documentos ainda 
são desprovidos de tratamento analítico, exigindo, assim, uma avaliação mais cuidadosa do pesquisador que dela se ocupa, além de permitir a ele ter uma relação direta com os fatos a serem analisados, de acordo com Moura Filho (2005).

Logo, fazer pesquisa requer o confronto entre dados, evidências e informações coletadas sobre determinado tópico, assim como o conhecimento teórico acumulado a respeito dele, como defendem Lüdke \& André (1986). Implica, portanto, implícita ou explicitamente, numa metodologia que assume pressupostos epistemológicos e numa concepção da realidade, mesmo quando o autor não a declara ou não apercebe. De acordo com Freitas (2013), "cabe ressaltar que fazer pesquisa envolve a difusão do conhecimento e também os agentes financiadores, portanto, é obrigação do pesquisador agir eticamente, durante e ao final de seu estudo (p. 33).

Assim, ao concluir uma metapesquisa, deve-se informar desvios e direções alternativas e, acima de tudo, comunicar de forma honesta, adequada, consistente e profissional sobre a produção, no caso específico, este artigo. Outro ponto relevante é que a metapesquisa apresenta a conjunção de um grupo de investigações em particular, tratando-se de um gênero que transcende as conclusões e interpretações dos estudos individualmente.

A metapesquisa procura integrar pesquisa empírica com o sentido de criar generalizações, o que implica a noção de buscar também os limites para ela. Frequentemente, a metapesquisa se atenta a teorias relevantes, analisa criticamente as pesquisas das quais tratam e procuram resolver conflitos na literatura, além de buscar identificar as questões centrais para futuras pesquisas, de acordo com Cooper et al. (2009). Ela persegue a compreensão sistemática a respeito de determinado problema utilizando, para isso, estudos primários, integrando evidências de pesquisa disponível, neste caso se utilizando da análise documental. Na LA, especificamente, eis uma prática relativamente nova, mas é necessário começar a pensar e agir sistematicamente para que a área possa trazer contribuições à compreensão humana do fenômeno de aprender e ensinar línguas, conforme Norris \& Ortega (2006). 
Em princípio, pode parecer que a metapesquisa se assemelha ao estado-da-arte; entretanto, essas perspectivas de pesquisa se diferenciam tanto na sua elaboração e condução quanto nos seus objetivos, no intuito de evitar ruídos metodológicos. Freitas (2013, p. 39) apresenta "uma comparação entre as duas, expondo as principais características que as diferenciam", sendo que em tal comparação, a metapesquisa transcende as conclusões dos estudos individuais que compõem o corpus, colocando em evidência as características e dados e não as conclusões dos estudos individuais; ela compila também resultados e busca generalizações por meio do exame de categorias de dados que perpassam os estudos. Já o estado-da-arte apresenta a condição de um conhecimento científico, acadêmico ou tecnológico em um período específico, salientando os resultados dos estudos individuais, e constrói uma espécie de linha do tempo que contextualiza o objeto da pesquisa.

A premissa fundamental da interpretação da metapesquisa é de que as análises primárias se transformam em dados que possibilitam o cruzamento de estudos que compartilham do mesmo foco. Os resultados de estudos individuais se convertem em valores passíveis de comparação via estimativa da magnitude de uma relação ou efeito observado. Uma vez que os dados sejam padronizados, seus resultados podem ser comparados ou combinados, em conformidade com Norris \& Ortega (2006).

Ao lançar mão dessa metodologia, ambiciona-se evidenciar os processos de mediação na apropriação da oralidade em LE - idioma Francês tendo como mediadores o texto teatral, o corpo e a voz e indicar, se possível, um novo referencial teórico norteador das práxis em sala de aula e/ou em outros ambientes de ensino-aprendizagem.

Integra também este artigo a origem da abordagem hermenêuticafenomenológica e as fundamentações de Paul Ricoeur e de Hans Georg Gadamer, bem como o nosso posicionamento como pesquisadores hermeneutafenomenológicos, além dos princípios da metapesquisa qualitativa na modalidade de análise documental.

\section{Hermenêutica - Origem}


No sentido mais restrito e mais usual do termo, a hermenêutica serve atualmente para caracterizar o pensamento de autores como Hans-Georg Gadamer e Paul Ricoeur, que desenvolveram uma "filosofia universal da interpretação e das ciências humanas que acentua a natureza histórica e linguística de nossa experiência de mundo", de acordo com Grondin (2012, p. 11).

De um lado, esses pensamentos marcaram uma grande parte dos debates intelectuais que balizaram a segunda metade do século XX (estruturalismo, crítica das ideologias, desconstrução, pós-modernismo, dentre outros), recepções que fazem parte daquilo que pode ser chamado, ainda segundo Grondin (2012), de o pensamento hermenêutico contemporâneo.

De outro, os pensamentos de Gadamer e Ricoeur e de seus seguidores, frequentemente, vinculam-se à tradição mais antiga da hermenêutica, quando ela ainda não designava uma filosofia universal da interpretação, mas, sim, simplesmente, a arte de interpretar corretamente os textos. No item seguinte, serão tratadas as concepções do termo hermenêutico ao longo dos tempos.

De acordo com Terra et al (2009), a origem da palavra hermenêutica dá-se no verbo grego hermeneuin, que significa interpretar, e também no substantivo hermeneia, que denota interpretação. Tem-se também como justificativa para o surgimento do termo, a ligação ao deus-mensageiro-alado Hermes, da mitologia grega, que está associado à função de tornar compreensível, principalmente quando envolve a linguagem humana (textual, oral e gestual) de maneira que a inteligência possa compreender.

Há outra orientação do termo hermenêutica, que sugere explicação. Nesse sentido, destaca-se o discurso da compreensão, pois as palavras vão além do dizer: elas explicam, racionalizam e clarificam algo. $O$ significado, portanto, está relacionado a alguém e ao contexto. É esta ligação que estabelece o significado. Assim, para Grondin,

não é por acaso que as principais regras hermenêuticas foram frequentemente extraídas da retórica, a arte do bem dizer, que se funda na ideia de que o pensamento que se procura comunicar deve ser apresentado de maneira eficaz no discurso. É especialmente o caso da importante regra hermenêutica do todo e das partes, segundo a qual as partes de um escrito devem 
se entendidas a partir do todo constituído por um discurso e por sua intenção geral (2012, p. 19).

Segundo esse estudioso, podem-se distinguir três grandes acepções possíveis da hermenêutica, que se sucederam no decorrer da história, embora se mantenham, integralmente, como concepções absolutamente atuais e defensáveis da tarefa hermenêutica. No sentido clássico do termo, a hermenêutica designava, outrora, a arte de interpretar os textos. Essa arte se desenvolveu, sobretudo, no seio das disciplinas ligadas à interpretação dos textos sagrados ou canônicos: a teologia (que elaborou uma hermenêutica sacra), o direito (hermenêutica iuris) e a filologia (hermenêutica profana). A hermenêutica desempenhava, então, na primeira concepção, uma função auxiliar, no sentido de vir a secundar uma prática da interpretação, que tinha necessidade, sobretudo, de um socorro hermenêutico ao enfrentamento de passagens ambíguas (ambigua) ou chocantes.

A hermenêutica, ainda na primeira concepção, possuía um objetivo essencialmente normativo: propor regras, preceitos ou cânones que permitissem interpretar os textos. Assim, a maioria das regras era tomada de empréstimo da retórica, uma das ciências fundamentais do trivium (ao lado da gramática e da dialética) e no seio da qual se encontravam com frequência reflexões hermenêuticas sobre a arte de interpretar.

Essa tradição, que fez da hermenêutica uma disciplina auxiliar e normativa nas ciências que praticam a interpretação, persistiu até Friedrich Schleiermacher (1768 - 1834). Mesmo este autor ainda fazendo parte da tradição, seu projeto de uma hermenêutica mais universal anuncia uma segunda concepção da hermenêutica, que será inaugurada sobretudo por Wilhelm Dilthey (1833 - 1911). De acordo com Grondin,

Dilthey conhece bem a tradição mais clássica da hermenêutica e sempre a pressupõe, sem deixar de enriquecê-la com uma nova tarefa: se a hermenêutica se inclina sobre as regras e os métodos das ciências do entendimento, ela poderia servir de fundamento metodológico a todas as ciências humanas (letras, história, teologia, filosofia e aquilo que hoje se chama de as "ciências sociais"). A hermenêutica se torna, assim, uma refle- 
xão metodológica sobre a pretensão de verdade e o estatuto científico das ciências humanas(2012, p. 13).

Sendo assim, a reflexão se eleva contra o pano de fundo do desenvolvimento pelo qual passaram as ciências "puras" no século XIX, sucesso amplamente atribuído ao rigor de seus métodos, diante dos quais as ciências humanas pareciam muito deficientes. Se as ciências humanas quisessem se tornar ciências respeitáveis deveriam se basear em uma metodologia que coubesse à hermenêutica fazer surgir para tanto legitimar ou dar o devido grau de respeito e confiabilidade às ciências humanas. Tem-se aí uma visão metodológica da hermenêutica que perdurou por muitos anos até o advindo da terceira concepção.

A terceira grande concepção nasceu, muito claramente, em contrapartida à compreensão metodológica da hermenêutica. Ela assume a forma de uma filosofia universal da interpretação. Sua ideia fundamental, de acordo com Grondin (2012), (prefigurada no último Dilthey ${ }^{2}$ ) é que o entendimento e a interpretação não são apenas métodos encontráveis nas ciências humanas, mas processos fundamentais que podemos encontrar no próprio núcleo da vida. A interpretação surge então, cada vez mais, como uma característica essencial de nossa presença no mundo e a função da hermenêutica é, através de seus métodos, transpor, por meio da linguagem, as pistas ou as dicas para o entendimento do fazer da humanidade.

A ampliação do sentido da interpretação é responsável pelo avanço do qual a hermenêutica do século XX se beneficiou. Esse avanço pode invocar

\footnotetext{
${ }^{2}$ Segundo Grondin (2012), tem-se três momentos distintos do pensamento de Wilhelm Dilthey (1833-1911), a saber: i) o momento de passagem da hermenêutica de filosofia para o campo de metodologia das ciências humanas sobre categorias que lhes sejam próprias (lógica), sobre uma teoria do conhecimento (epistemologia) e sobre uma teoria do método específico; ii) a hermenêutica como metodologia do entendimento histórico dos indivíduos, sendo "a arte da interpretação das manifestações vitais fixadas por escrito". O objetivo da interpretação é entender a individualidade a partir de seus sinais exteriores. iii) na última fase, a universalidade da hermenêutica ou do reino da interpretação consiste em que o entendimento e a interpretação não são apenas "métodos", mas traduzem uma busca de sentido e de expressão ainda mais originária da própria vida, através das várias formas de expressão que as ciências humanas buscam entender recriando a experiência da qual elas brotam. Para mais informações, vide GRONDIN, J. Hermenêutica. Trad.: Marcos Marcionilo. São Paulo: Parábola, 2012, pp. 32-36.
} 
"dois padrinhos, Nietzsche (anônimo porque ele não falou muito de hermenêutica) e sua filosofia universal da interpretação, e um padrinho mais evidente em Heidegger" (Grondin, 2012, p. 14). Mesmo que este último filósofo defenda uma concepção particular da hermenêutica clássica e metodológica, seu entendimento é de que ela não tem, em princípio, a ver com textos, mas com a própria existência, que já é penetrada por interpretações que a hermenêutica pode esclarecer. A hermenêutica se vê, então, posta a serviço de uma filosofia da existência, chamada a um autodespertar. Passa-se aqui de uma "hermenêutica de textos" para uma "hermenêutica da existência".

A maior parte dos grandes representantes da hermenêutica contemporânea (Gadamer, Ricoeur, dentre outros) situa-se na trilha de Heidegger, mas não seguiram realmente sua "via direta" de uma filosofia da existência. Eles preferiram retomar o diálogo com as ciências humanas, mais ou menos negligenciado por Heidegger.

Assim, reataram com a tradição de Schleiermacher ${ }^{3}$ e Dilthey, sem com isso diminuir a ideia de que a hermenêutica estava, por princípio, investida de uma função metodológica. Seu objetivo era, especialmente, desenvolver uma melhor hermenêutica das ciências humanas, aliviada do paradigma exclusivamente metodológico, que faz mais jus à dimensão linguística e histórica do entendimento humano. Ao assumir a forma de uma filosofia universal do entendimento, esta hermenêutica acabou por deixar o terreno de uma reflexão sobre as ciências para criar uma pretensão de entendimento universal das ciências.

\section{Ricoeur - Hermeneuta-fenomenológico}

\footnotetext{
${ }^{3}$ Friedrich Schleiermacher (1768-1834), contemporâneo dos grandes pensadores do idealismo alemão -Fichte, Hegel e Schelling -, foi, ao mesmo tempo, um grande filólogo, um teólogo expressivo, um filósofo e um teórico da hermenêutica. Porém, ele apenas será destacado neste artigo enquanto hermeneuta. Schleiermacher inspirou-se em grande medida na tradição retórica deque "todo ato de entendimento é uma inversão de um ato de discurso em virtude da qual deve ser trazido à consciência o pensamento que se encontra na base do discurso". Assim, a hermenêutica, segundo esse autor, divide-se em duas grandes partes: a interpretação gramatical, que entende todo discurso a partir de uma língua dada e de sua sintaxe, e a interpretação psicológica (eventualmente chamada de "técnica"), que tem no discurso a expressão de uma alma individual. Para mais informações, vide GRONDIN, J. Hermenêutica. Trad.: Marcos Marcionilo. São Paulo: Parábola, 2012, pp. 23-31.
} 
Com base nas obras de Paul Ricoeur, mais especificamente em $O$ conflito das interpretações (1978), Interpretação e ideologias (1990) e Teoria da interpretação (1976), pretende-se mostrar as contribuições do seu pensamento a partir da compreensão de alguns traços de seu discurso.

Para Ricoeur (1989), a hermenêutica é uma fonte metodológica para a compreensão de obras teóricas ou poéticas, configurando-se como um instrumento e um guia para a assimilação de discursos filosóficos, políticos, pedagógicos e nas ações e construções racionais ou poéticas. Sendo assim, a hermenêutica, como instrumento de compreensão do discurso ou da ação, configurase como um laço mimético que se caracteriza como "uma articulação daquilo que chamamos compreensão, no sentido heideggeriano de articulação significante da estrutura compreensível do ser-no-mundo" (1989, p. 100). Por isso, toda obra tem caráter simbólico, seja um discurso (uma linguagem) ou uma palavra, e necessita da mediação simbólica do mito, da poesia ou do símbolo.

Outro ponto que se deve levar em consideração em Ricoeur é a relação entre fenomenologia e linguagem, sendo fundamental considerar a noção de tempo. Na fenomenologia, há um tempo reflexivo ou tempo subjetivo - tempo da alma; na linguística, diz-se que há um tempo cosmológico ou tempo objetivo - tempo do mundo. Assim, pode-se considerar que o tempo reflexivo é o tempo do sujeito; e o tempo cosmológico é o tempo do mundo; tempos, no entanto, que se complementam e formam aquilo que se pode denominar tempo do ser no mundo-do-texto, expressão deste autor.

Para Ricoeur (1989; 1990), linguagem, discurso da ação, signos mediadores, cultura e suas manifestações são vias que devem desembocar na hermenêutica ou na teoria geral da interpretação. Tal teoria afigura-se como instrumento metodológico, epistemológico, ontológico e pedagógico, dado que não se restringe apenas a uma opção ou um procedimento metodológico, mas que, fundamentalmente, possibilita ao investigador/pesquisador ter uma visão de construção do conhecimento metodológico, uma compreensão de obras e organização da vida humana para além dos textos. Além disso, deve haver preocupação com o que existe no texto e com o que o texto convoca, ou seja, com aquilo que remete o indivíduo para o sentido do texto. 
O discurso, também para Ricoeur (1989, p. 117), é uma "sequência de frases, é feito de frases e é maior do que uma frase", por isso, ao (de)codificálo, busca-se compreender e perceber gênero e estilo, isto é, apreender o acontecimento e o sentido por ele apresentados. É fundamental mostrar que, em qualquer obra, há um laço mimético ou implicações profundas estabelecidas entre a palavra e a ação, e é justamente este laço mimético que se configura, no texto, como uma refiguração da ação do texto e da interpretação.

Tal laço permite revelar também o leitor e/ou intérprete de um texto, assim como ajuda o imaginário criador a manter o sentido objetivo de uma escrita. Nesse contexto, a hermenêutica caracteriza-se como um instrumento valioso, tanto nas construções imaginárias, como na Filosofia, na Educação ou nas Ciências, visto que funciona como instrumento de análise e compreensão de obras.

As ações que suscitam o imaginário social estão embasadas nos paradigmas da ação e dos discursos, que são capazes de aflorar possibilidades ontológicas. O imaginário funciona como ligação profunda e anímica do sujeito com seu inconsciente - considerado na Psicanálise como o lugar de resíduos de energias, mas também de forças propulsoras para a manutenção e organização da vida (Tavares, 2010). Diz-se que é no inconsciente que brotam as energias fundamentais para a sobrevivência e para as mais variadas formas e expressões criadoras. É de igual valia, de acordo com Silva,

lembrar que é também no inconsciente que os desvios e distorções são construídos. Por isso, a noção de inconsciente é fundamental nessa perspectiva, visto que, para Ricoeur, é do inconsciente que brotam as expressões maiores do imaginário social, tais como a ideologia e a utopia, que possibilitam, por exemplo, compreender a educação sob a via das mediações simbólicas, de acordo com as ações dos indivíduos, grupos, classes e sociedade (2011, p. 21).

O inconsciente e o imaginário, na perspectiva hermenêutica, são relevantes para a compreensão da problemática de um texto. Esta começa quando o indivíduo se pergunta como fazer para seguir uma história ou, melhor, o que fazer para ver uma ação ou o ser dessa ação se manifestar. Trata-se de situa- 
ção que requer, segundo o autor, uma construção específica a fim de compreender uma história, sendo necessário refazer a operação discursiva do texto. Quando alguém recorre à explicação de um texto, procura evidenciar nele as implicações, ou seja, as intrigas do texto.

Ricoeur faz cinco considerações sobre a hermenêutica. A primeira refere-se a ela como um enxerto (preenchimento), já que surgiu antes da fenomenologia de Husserl. A hermenêutica foi classificada, inicialmente, no limite da exegese, isso é, em disciplina que tinha como fim compreender os textos sagrados que não eram de fácil acesso e, por conseguinte, sua compreensão era limitada a poucos.

Na segunda consideração, a hermenêutica é tida como a ciência de toda a compreensão linguística que se baseia na concepção de todos os tipos de interpretação de textos. Nesta, marca-se o início da hermenêutica não disciplinar e define-se como estudo da sua própria compreensão.

Na terceira, a hermenêutica também é considerada como alicerce metodológico dos Geisteswissenschaften (ciência humana), referindo-se ao projeto de Wilhelm Dilthey. Este percebera que a hermenêutica poderia servir de base a todas as disciplinas que estivessem centradas na compreensão da arte, no comportamento e na escrita do homem.

Dilthey defendia a interpretação das expressões essenciais da vida humana, pois são plausíveis de uma compreensão histórica, porém diferentemente da quantificação e da cientificidade do mundo natural (Naturwissenschaften). Dilthey achou na hermenêutica uma metodologia humanística.

A quarta consideração refere-se à fenomenologia do Dasein (existência) e da compreensão existencial. Martin Heidegger, ao desenvolver seu estudo sobre a presença cotidiana do ser humano no mundo, chamou para análise, em sua obra, uma hermenêutica do Dasein. Nesse âmbito, a hermenêutica é considerada como uma explicação fenomenológica da existência humana e não uma ciência ou regras de interpretação de textos, tampouco uma metodologia para a Geisteswissenschaften.

Após Heidegger, Hans-Georg Gadamer delineia detalhadamente o desenvolvimento da hermenêutica, desde os estudos iniciais para despertar a 
consciência filosófica da Geisteswissenschaften. Para Gadamer, no relato de Lawn (2007), a compreensão é relacionada à experiência estética e ao conhecimento histórico na hermenêutica. Isso mostra que a compreensão precisa, segundo ele, estar inserida num contexto no qual haja uma fusão constante do passado e do presente. Partindo da contribuição de Gadamer, Araújo afirma que

não há como evitar a inserção, o pertencimento à história como prévio a todo conhecimento ou ciência. Primeiramente o ser é histórico, pertence a uma época. Neste sentido, fica inaceitável a dicotomia entre explicar (ciências da natureza) e compreender (ciências do espírito) de Dilthey (1998, p. 196).

Logo, a compreensão dá-se através da interpretação da vida que brota na história. Cada época produz significações cujo entendimento e sentido é preciso compreender. Gadamer (2011), todavia, observa que o que vem em primeiro lugar não é a reflexão acerca do sentido dado em cada época; a relação primeira é a do ser com a realidade, uma relação de pertencimento à história. Esta é a verdade do ser humano, de acordo com ele.

Por fim, na quinta consideração, como sistema de interpretação, a hermenêutica é compreendida como um processo que interpreta um conteúdo e um significado manifesto ou escondido. Ricoeur, nesta concepção, contribui significativamente quando refere que a hermenêutica é o processo pelo qual o significado é desvelado para além do conteúdo manifesto. Com isso, pode-se dizer que, hoje, a hermenêutica está pautada na linguagem.

Em tal contexto, para Ricoeur (1976; 1990), a linguagem é fundamental para a compreensão das áreas de estudos que se beneficiam dos seus preceitos filosóficos. Ela permite falar de mundos diversificados, por isso são de grande valia as disciplinas que estudam a linguagem, como é o caso da Psicologia, da Sociolinguística, da Análise do Discurso (AD), da LA, dentre outras, por apontar a cultura como o cerne da linguagem. Quanto à Psicanálise, podese observar que ela é mais que uma interpretação de culturas, é também um modelo pertinente de interpretação, conforme afirma Tavares (2010). 
Ao considerar os elementos dos desejos e dos sonhos, a linguagem pode revelar e também dissimular por meio de uma "linguagem distorcida"; ainda assim, coloca em evidência uma região específica da cultura que pede por um duplo sentido, em que não se podem eliminar as ambiguidades, uma vez que desejos ou sonhos, ao serem contados, abrem possibilidades para a construção de um contexto coerente de signos a serem interpretados. Isso significa que, ao elaborar uma atividade de interpretação, seja qual for a natureza dela, pode-se colocá-la em evidência e distinguir o símbolo.

O desafio em Ricoeur é realizar a linguagem criativamente. Considerase que sua teoria da interpretação, hermenêutica, está alicerçada na dialética entre explicação e compreensão, mediada pela interpretação, seguindo um método reflexivo que faz uma aliança com o vivido, como bem exemplificada por Silva ao dizer que

como em toda cultura, há mediação simbólica da ação que se sobressai pela manifestação da linguagem, a qual acaba por revelar a reflexão sobre o ser. Compreender o ser é compreender suas relações com essas mediações, que são anteriores ao ato mesmo da compreensão, cuja função é fazer pensar, transformar visões de mundo, ou seja, colocar em funcionamento a consciência reflexiva (2011, p. 22).

Assim, a hermenêutica trata de uma congruência que propõe reflexões sobre a experiência estética e sobre a linguagem humana. É a interpretação do sentido do não dito ou mostrado ao fazer-se algo. Mostra-se como uma tentativa de especificar o significado que é primordial na descrição da experiência.

A finalidade da hermenêutica é alcançar uma teoria da interpretação do ser. Por isso, Paul Ricoeur busca um "método reflexivo" que esclarece a existência e elucida "seu sentido". Em seu método reflexivo, entende-se que compreender e explicar não se excluem mais mutuamente, mas se completam. Sozinha, a explicação restringe o sentido em sua riqueza, pois exila a obra a uma simples estrutura. Esta serve apenas como intermediária para o discurso; a partir do discurso é que se tem compreensão.

\section{Gadamer - hermeneuta-fenomenológico}


Outra forma radicalmente diferente de representar a noção de compreensão interpretativa é encontrada na hermenêutica filosófica de Gadamer, inspirada no trabalho de Heidegger, que define o papel do intérprete como um indivíduo engajado em análise crítica ou explicação de um texto (ou de alguma ação humana).

Segundo Gadamer (1970), a compreensão é a interpretação. Ela não é uma atividade isolada executada pelos seres humanos, mas uma estrutura básica de nossa experiência de vida, pois, segundo o filósofo, estamos sempre tomando algo por algo. $\mathrm{O}$ ato de interpretar (ou tomar algo por algo) não deve desconsiderar as intencionalidades ou os preconceitos sócio-históricos com uma característica ou um atributo do qual o intérprete deva livrar-se ou que ele deva se empenhar para controlar a fim de chegar a uma compreensão "clara".

A compreensão é participativa, conversacional e dialógica, mantendo sempre uma estreita ligação com a linguagem, sendo conquistada, por vezes, através de uma lógica de pergunta e resposta. Além disso, a compreensão é algo produzido neste diálogo e não algo reproduzido por um intérprete/participante por meio de uma análise do diálogo que ele procura compreender.

Ao mesmo tempo em que a compreensão é participativa, conversacional e dialógica ela revela que a historicidade é comunicação na e pela interação entre os participantes. Isto porque a linguagem só se torna efetiva enquanto discursiva. Não é simplesmente fruto de regras, mas sim fala efetiva.

A diferente concepção do significado representa uma ruptura radical com a ideia interpretativista de que a ação humana possui significado e de que o significado pode ser, em princípio, determinado ou decidido pelo intérprete/participante. Em outras palavras, o significado é negociado mutuamente no ato da interpretação, não é simplesmente descoberto. Berstein resume bem a noção proposta por Gadamer do caráter progressivo, aberto, preventivo, da formação do significado, ao dizer que 
bém vêm sofrendo mudanças no curso da história. É por isso que Gadamer nos diz que compreender é sempre compreender de uma maneira diferente. Mas isso não significa que nossas interpretações sejam arbitrárias e deturpantes. Devemos sempre visar a uma compreensão correta do que dizem as "coisas em si mesmas" (os objetos de nossa interpretação). Porém, o que as "coisas em si mesmas" dizem será diferente à luz de nossos horizontes mutáveis e das diferentes perguntas que aprendemos a fazer (1983, p. 139). ${ }^{4}$

De acordo com tal síntese, a compreensão é ela mesma um tipo de experiência prática no e sobre o mundo que, parcialmente, constitui os tipos de pessoas que somos no mundo. Por isso, Gadamer nos diz que compreender é sempre compreender uma maneira diferente.

A interpretação envolve mais que investigação filosófica das origens históricas e significados das palavras, ela pode ser vista como um elemento no processo, no ato ou evento do entendimento em si. Esta é uma das contribuições mais importantes de Gadamer ao pensamento contemporâneo. Seu compromisso com a ideia de que todo o entendimento é interpretação demonstra que a hermenêutica-fenomenológica vai além dos limites da interpretação textual.

Na realidade, para Gadamer, segundo Lawn (2007), a hermenêuticafenomenológica é universal: aquilo que acontece quando se interpreta um texto é o que acontece quando se procura entender qualquer coisa em nosso mundo sociocultural, seja o significado da vida ou uma interpretação mais comum dos objetos do cotidiano, das ideias e situações. Com isso, a leitura é interpretação, olhar é interpretação, pensar é interpretação; interpretação não é uma atividade especial restrita à elucidação de textos difíceis, ela é um aspecto de todas as formas do entendimento humano.

\footnotetext{
${ }^{4}$ [...] we always understand and interpret according to our preventive preconceptions and prejudices, which have also been changing throughout history. That is why Gadamer states that understading is always comprehending in another way. However, it does not mean that our interpretations are arbitrary and misleading. We should always aim an accurate understanding of what "things within themselves" say (the object of our interpretation). Nonetheless, what "things within themselves" say are different in the light of our mutable horizins and the different questions we learn to ask. (BERSTEIN, 1983, p. 139) (versão nossa)
} 
Agora, após algumas explanações e esclarecimentos sobre o enquadramento desta pesquisa - metapesquisa - de orientação qualitativa, na modalidade de análise documental no uso da perspectiva da hermenêuticafenomenológica de Ricoeur e de Gadamer, cabe salientar nosso posicionamento como pesquisadores travestidos metodologicamente de hermeneutafenomenológicos que mescla as considerações dos hermeneutas do fenômeno citados aqui.

\section{Considerações finais}

A hermenêutica-fenomenológica, como instrumento metodológico do discurso ou da ação, configura-se um elemento que se caracteriza como articulação daquilo que se chama de compreensão. Tal teoria é um instrumento metodológico, epistemológico, ontológico e pedagógico, dado que não se restringe apenas a uma escolha ou um posicionamento metodológico, mas que, primordialmente, possibilita a um pesquisador hermeneuta-fenomenológico ter uma visão da construção do conhecimento metodológico dos professores pesquisadores em tela.

A compreensão, no caso do presente artigo, refere-se às produções primárias e organização das práxis para além dos textos de Massaro e Reis. Logo, a compreensão é, ela mesma, um tipo de experiência prática no e sobre o mundo que, parcialmente, constitui os tipos de pessoas que somos no mundo. Por isso, acredita-se que compreender é sempre compreender uma maneira diferente, considerando que a teoria da interpretação, hermenêuticafenomenológica, está alicerçada na dialética entre explicação e compreensão mediada pela interpretação.

Transformadas estão também as nossas relações com a atividade que faz parte de nossa vida profissional: ensinar e aprender uma Língua Estrangeira, justamente pelo método da hermenêutica-fenomenológica de Ricoeur e de Gadamer aplicada a esta pesquisa, não só pelo ineditismo de tal metodologia na Linguística Aplicada, mas também pelo fascínio das subjetividades desses autores. 


\section{Referências}

BERNSTEIN, R. J. Beyond objectivism and relativism: science, hermeneutics, and praxis. Philadelphia: University of Pennsylvania Press, 1983.

CHIZZOTTI, A. Pesquisa qualitativa em ciências humanas e sociais. Petrópolis-RJ: Vozes, 2006.

COOPER, H. M.; HEDGES, L. V.; \& VALENTINE, J. C. The handbook of research

synthesis and meta-analysis. 2nd ed. New York: Russel Sage Fundation, 2009.

FLICK, U. "Redação e o futuro da pesquisa qualitativa: arte ou método?" Em FLICK, U. Introdução à pesquisa qualitativa. Porto alegre: Artmed, 2009.

FRANCO, S. de G. Hermenêutica e psicanálise na obra de Paul Ricoeur. São Paulo: Loyola, 1995.

FREITAS, M. S. Daquilo que sabemos: pesquisa metateórica sobre abordagem de ensino de línguas. Dissertação de mestrado. 111f. Mestrado em Linguística Aplicada. LET-UnB. Brasília, 2013. Disponível em:

$<$ http://www.pgla.unb.br/index.php?option=com content\&view=article\&id=444: mirelle-da-silva-freitas\&catid=42:2013\&ltemid=271 > acesso em 09 de dezembro de 2013.

GADAMER, H. G. Hermenêutica em retrospectiva. Tradução de Marcos Antônio Casanova. São Paulo: Vozes, 2010.

. On the scope and function of hermeneutical reflection. Tradução de G. B. Hess e Richard E. Palmer. Los Angeles: University California Press, 1977.

GRONDIN, J. Hermenêutica. Tradução de Marcos Marcionilo. São Paulo: Parábola, 2012.

LAWN, C. Compreender Gadamer. Tradução de Hélio Magri Filho. Rio de Janeiro: Vozes, 2007.

LÜDKE, M.; ANDRÉ, M. E. D. A. Pesquisa em educação: abordagens qualitativas. São Paulo: EPU, 1986.

MASSARO, P. R. O silêncio e a voz do texto teatral em francês, língua estrangeira. Tese de doutorado. 232f. Doutorado em Letras. FFLCH-USP. São Paulo, 2007. Dispo-nível em: <http://ebookbrowse.com/tese-paulo-robertomassaro-pdf-d60227168> acesso em 15 de janeiro de 2012.

. Teatro e língua estrangeira, entre teoria(s) e prática(s): percursos entre o vislumbre e o olhar. Dissertação de mestrado. 207f. Mestrado em Letras. FFLCH-USP. São Paulo, 2001. 
Teatro e língua estrangeira - entre teoria(s) e prática(s). São Paulo: Paulista-na, 2008.

MERRIAM, S. B. Qualitative research and case study applications in education: revised and expanded from Case Study Research. São Francisco, California: Jossey-Bass Publishers. 1998.

MOURA FILHO, A. C. L. Reinventando a aula: por um contexto cooperativo para aaprendizagem de inglês como língua estrangeira.161p. Dissertação (Mestrado em Linguística) - LIP-UnB, Brasília, 2000. Disponível em $<$ http://repositorio.unb.br/bitstream/10482/1541/1/Dissertacao Augusto Cesar L Moura Filho.pdf> acesso em 22 de julho de 2013.

Pelo inglês afora: carreira profissional e autonomia na aprendizagem de inglês como língua estrangeira. 281p. Tese (Doutorado em Linguística Aplicada) - FALE-UFMG, Belo Horizonte, 2005. Disponível em $<$ http://repositorio.unb.br/bitstream/10482/1554/1/Tese Augusto Cesar L Mou ra Filho.pdf> acesso em 22 de julho de 2013.

NORRIS, J. M.; ORTEGA, L. (orgs.) Synthesizing Research on Language Learning and Teaching. Philadelphia: John Benjamins Publishing Company, 2006.

PELLAUER, D. Compreender Ricoeur. Tradução de Marcus Penchel. Rio de janeiro: Vozes, 2009.

REIS, M. G. M. O texto teatral e os jogos dramáticos no ensino de francês língua estrangeira. Tese de doutorado. 259f. Doutorado em Letras. FFLCHUSP. São Paulo, 2008.2 Disponível em:<http://www.teses.usp.br/teses/disponiveis/8/8146/tde-02122008-

171004/pt-br.php > acesso em 10 de novembro de 2011.

"A expressão em cena: afetividade, o corpo, e a voz da LE". Em MASTRELLA DE ANDRADE, M. R.(org.) Afetividade e emoções no ensino/aprendizagem de línguas: múltiplos olhares. Campinas-SP: Pontes, vol. 18. 2011.

.; FERREIRA, A. M. A. Verbetes oral, oralidade e discurso: análise crítica de dois dicionários didáticos de ensino de língua estrangeira/oral. Em Revista Signum: Estudos Linguísticos. Londrina-PR, n. 15, vol. 2, dez. 2012.

RICOEUR, P. Teoria da interpretação. Tradução de Artur Morujão. Lisboa: Edições 70, 1976.

O conflito das interpretações: ensaios de hermenêutica. Tradução de Hílton Japiassu. Rio de Janeiro: Imago, 1978.

. Interpretação e ideologias. Tradução de Milton Japiassu. $4^{a}$ ed. Rio de Janeiro: Francisco Alves, 1990.

. Do texto à acção: ensaios de hermenêutica II. Tradução de Alcino Cartaxo e Maria José Sarabando. Porto: Rés-Editora, 1989. 
SANTOS, M. S. A construção de identidades no livro didático de língua estrangeira: uma perspectiva crítica. Dissertação de Mestrado. 239f. Mestrado em Linguística Aplicada. LET-UnB. Brasília, 2013. Disponível em: $<$ http://pgla.unb.br/index.php?option=com content\&view=article\&id=435:marcel o-sousa-santos\&catid=42:2013\&ltemid=271> acesso em 13 de setembro de 2013.

SILVA. L. B. O. A interpretação hermenêutica em Paul Ricoeur: uma possível contribuição para a educação. Comunicações. Piracicaba-SP. Ano 18, n. 02. jul./dez. 2011. Disponível em: <https://www.metodista.br/revistas/revistasunimep/index.php/comunicacao/article/download/131/595> acesso em 18 de outubro de 2012.

TERRA, M. G. et al. Fenomenologia-hermenêutica de Paul Ricoeur como referencial metodológico numa pesquisa de ensino em enfermagem. Acta Paulista de Enfermagem. vol. 22, n. 1. São Paulo, jan./fev., 2009. Disponível em: <http://www.scielo.br/pdf/ape/v22n1/a16v22n1.pdff acesso em 12 de janeiro de 2012. 